\title{
W. C. DE LEEUW
}

Nous venons de perdre notre cher ami W. C. DE Leeuw, un des fondateurs de la Station Internationale de Géobotanique Méditerranéenne et Alpine. Il fût l'un des premiers ayant compris tout l'intérêt scientifique et pratique de la phytosociologie, qu'il a toute sa vie soutenu de ses efforts désintéressés et c'est en grande partie grâce à son intervention que les études phytosociologiques se sont très tôt implantées dans les Pays-Bays.

Lors de la création de la Station de Montpellier, il fut pour nous d'un grand secours. Lors de la session inaugurale de la S.I.G.M.A. à Cambridge (26 août 1930) il fut unanimement désigné comme secrétaire, fonction qu'il a gardée pendant une trentaine d'années. Ami sûr et fidèle il n'a cessé de nous soutenir et ses conseils nous ont été précieux pendant les bons et mauvais jours.

Pour étendre ses connaissances géobotaniques, il a participé activement à plusiers excursions organisées par notre Station: dans le Midi de la France, dans les Alpes suisses, aux Pays-Bas. Connaissant parfaitement le tapis végétal de la côte hollandaise, il s'est alors joint à nous pour décrire les groupements végétaux de l'Ile d'Ameland et leur évolution, première étude phytosociologique parue en Hollande, publiée en 1936 dans le Nederlandsch Kruidkundig Archief (communication de la S.I.G.M.A. no. 50).

Un souvenir inoubliable rattache tous ceux qui l'ont connu à notre fidèle ami disparu.

J. Braun-Blanguet 


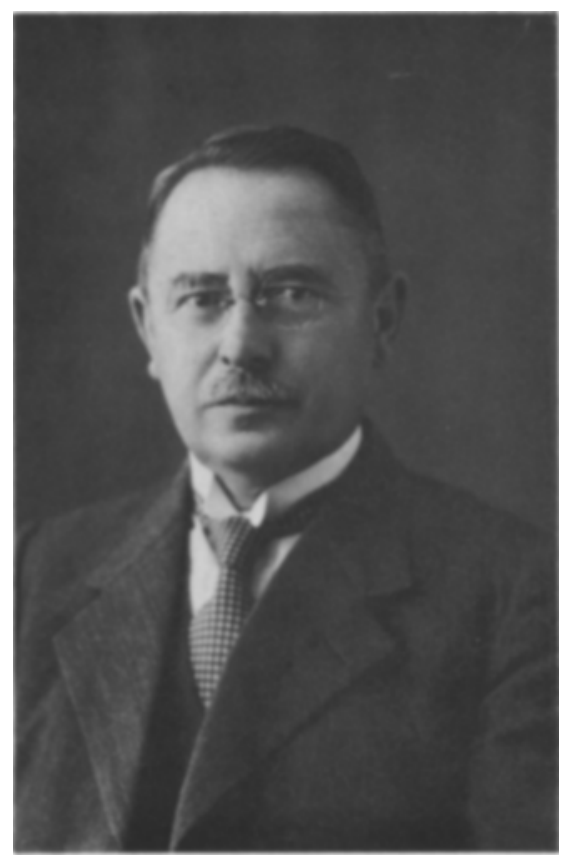

W. C. DE LEEUW 